\title{
OPEN Aligned CuO nanowire array for a high performance visible light photodetector
}

\author{
Min-Seung Jo ${ }^{1,6}$, Hyeon-Joo Song ${ }^{2,6}$, Beom-Jun Kim ${ }^{1,6}$, Yoo-Kyum Shin ${ }^{3}$, Sung-Ho Kim ${ }^{1}$, \\ Xu Tian ${ }^{4}$, Sang-Min Kim ${ }^{3}$, Min-Ho Seo ${ }^{3,5}$ \& Jun-Bo Yoon ${ }^{1 \bowtie}$
}

Recently, copper oxide (CuO) has drawn much attention as a promising material in visible light photodetection with its advantages in ease of nanofabrication. CuO allows a variety of nanostructures to be explored to enhance the optoelectrical performance such as photogenerated carriers scattering and bandgap engineering. However, previous researches neglect in-depth analysis of CuO's light interaction effects, restrictively using random orientation such as randomly arranged nanowires, single nanowires, and dispersed nanoparticles. Here, we demonstrate an ultra-high performance CuO visible light photodetector utilizing perfectly-aligned nanowire array structures. CuO nanowires with $300 \mathrm{~nm}$-width critical dimension suppressed carrier transport in the dark state and enhanced the conversion of photons to carriers; additionally, the aligned arrangement of the nanowires with designed geometry improved the light absorption by means of the constructive interference effect. The proposed nanostructures provide advantages in terms of dark current, photocurrent, and response time, showing unprecedentedly high (state-of-the-art) optoelectronic performance, including high values of sensitivity $(S=172.21 \%)$, photo-responsivity $(R=16.03 \mathrm{~A} / \mathrm{W}, \lambda=535 \mathrm{~nm})$, photo-detectivity $\left(D^{*}=7.78 \times 10^{11}\right.$ Jones $)$, rise/decay time $\left(\tau_{r} / \tau_{d}=0.31 \mathrm{~s} / 1.21 \mathrm{~s}\right)$.

Recently, visible light photodetectors have gained significant attention in scientific and industrial fields for a wide range of applications from traditional imaging, military monitoring, and optical communication to emerging technologies including environmental, biomedical, and wearable electronics ${ }^{1-4}$. As the field of application expands further, photodetectors with more functionality, such as transparency, flexibility, and broad absorption spectrum are required. Therefore, a wider range of materials including organic materials ${ }^{5,6}$, organic-inorganic hybrids $^{7}$, quantum $\operatorname{dots}^{8,9}, 2 \mathrm{D}$ nanomaterials ${ }^{10,11}$, and metal oxides ${ }^{12-14}$, have drawn attention in recent years as next-generation photodetector materials. Among various candidates, copper oxide $(\mathrm{CuO})$, which has a high optical absorption coefficient and the lowest band gap energy among metal oxides, is a promising material for visible light photodetectors with transparency and flexibility ${ }^{15-18}$. In particular, the structure dependent optoelectrical characteristics of $\mathrm{CuO}$, for example, its bandgap range and surface depletion layer for charge capturing, are controllable for suitable applications thanks to the material's ease of nanofabrication. This feature enables a broad range of applications, such as multispectral detection and molecular/thermal imaging. Moreover, the intrinsic chemical/mechanical stability and cost-effectiveness of $\mathrm{CuO}$ are attractive strengths that will lead to reliable devices even for industrial applications. In this regard, numerous studies have been performed to exploit $\mathrm{CuO}$ for photodetectors ${ }^{17-31}$. Nonetheless, the electrically conductive characteristics of $\mathrm{CuO}$, based on intrinsic hole accumulation at the surface, cause high dark current $\left(I_{\text {dark }}\right)$, resulting in unacceptably low sensitivity $(S)$, photo-responsivity $(R)$, and photo-detectivity $\left(D^{*}\right)$.

To improve the performance of $\mathrm{CuO}$ photodetectors, researchers have recently attempted to use $\mathrm{CuO}$ as a form of nanomaterial, such as nanoparticles (NPs) and nanowires (NWs). As the size of $\mathrm{CuO}$ is reduced to the nanometer scale, electrical resistivity can be dramatically increased due to the enhanced electron scattering, which favorably suppresses $I_{\text {dark }}$ and enhances optoelectronic performance ${ }^{19,21,22,32}$. However, attempts to

\footnotetext{
${ }^{1}$ School of Electrical Engineering, Korea Advanced Institute of Science and Technology (KAIST), 291 Daehak-ro, Yuseong-gu, Taejon 34141, Republic of Korea. 'SAMSUNG ELECTRONICS Co., Ltd., 1, Samsungjeonja-ro, Hwaseong-si, Gyeonggi-do 18448, Republic of Korea. ${ }^{3}$ Department of Information Convergence Engineering, College of Information and Biomedical Engineering, Pusan National University, Yangsan 50612, Republic of Korea. ${ }^{4}$ Department of Micro and Nanosystems, KTH Royal Institute of Technology, Brinellvägen 8, 114 28 Stockholm, Sweden. ${ }^{5}$ School of Biomedical Convergence Engineering, College of Information and Biomedical Engineering, Pusan National University, Yangsan 50612, Republic of Korea. ${ }^{6}$ These authors contributed equally: Min-Seung Jo, Hyeon-Joo Song and Beom-Jun Kim. ${ }^{\circledR}$ email: mhseo@pusan.ac.kr; jbyoon@kaist.ac.kr
} 
(a)

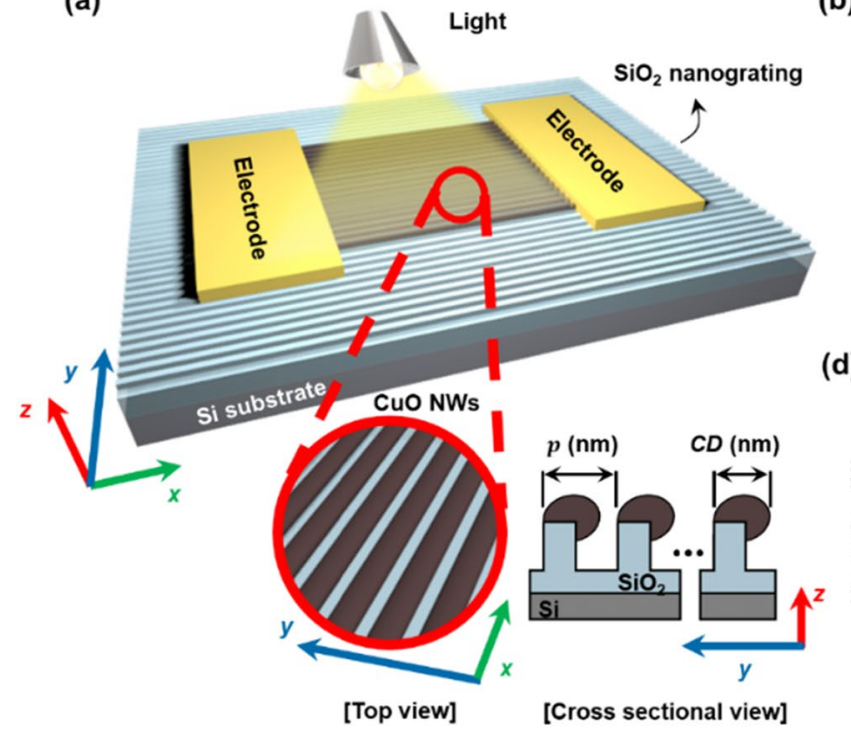

(b)

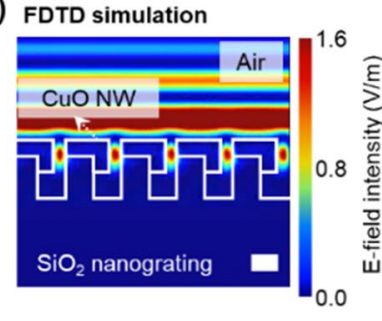

(d)

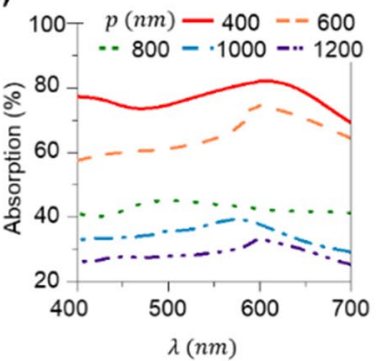

(c)

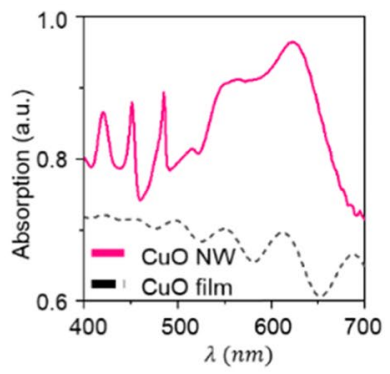

(e)

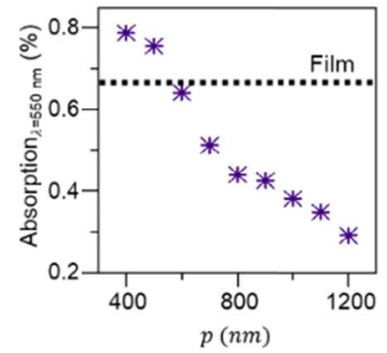

Figure 1. Concept of the proposed high-performance visible light photodetector. (a) 3-D schematic of the proposed device. The device is composed of the perfectly aligned $\mathrm{CuO}$ nanowire array (see [Top view]) on the $\mathrm{SiO}_{2}$ nanograting substrate (see [Cross sectional view]). (b) FDTD simulation result of the proposed device (scale bar $=200 \mathrm{~nm}$ ). (c) Calculated absorption of the $400 \mathrm{~nm}$-pitch $(p)$ of CuO nanowire (NW) array on $\mathrm{SiO}_{2}$ nanograting substrate (pink solid line). Black dashed line indicates the absorption of $\mathrm{CuO}$ thin film (thickness $=122 \mathrm{~nm}$ ). Calculated absorption varying pitch of $\mathrm{CuO} \mathrm{NWs}$ with same dimension on $\mathrm{SiO}_{2}$ nanograting from 400 to $1200 \mathrm{~nm}($ width $=314 \mathrm{~nm}$, thickness $=114 \mathrm{~nm}):(\mathbf{d})$ visible light range $(\lambda=400-700 \mathrm{~nm})$ (e) $\lambda=550 \mathrm{~nm}$.

improve the performance of $\mathrm{CuO}$ with conventional nanomaterial approaches have been limited; previous works have simply utilized $\mathrm{CuO}$ nanomaterials made by synthesis and dispersion, resulting in randomly dispersed $\mathrm{CuO}$ nanomaterials ${ }^{19,20,29}$. Unfortunately, these random $\mathrm{CuO}$ nanomaterials make irregular and undesignable networks, creating an additional current pathway and increasing $I_{d a r k}$. More importantly, these conventional nanomaterial methods limit the geometric design of nanomaterials, which is important for achieving additional performance enhancements in optical and photonic applications based on surface resonance ${ }^{33-36}$. Arbitrary shape also makes it difficult for $\mathrm{CuO}$ photodetectors to achieve uniform and reproducible device performance, which is crucial for practical usage of $\mathrm{CuO}$. Thus, a transition of research viewpoint that can lead to geometrically and structurally designable nanomaterials are necessary for high-performance $\mathrm{CuO}$ photodetectors. Emerging nanofabrication technologies now enable us to fabricate multi-dimensional and scalable nanomaterials with high degrees of geometrical and structural design. The resulting geometrically and structurally designed nanomaterials have shown unprecedented performance in diverse device-level applications $s^{37,38}$. Moreover, spatially designed nanomaterials have guaranteed device-scalability, uniformity, reproducibility, and high-throughput, which are essential to their use in devices at an industrial level. Yet, there have been no studies that have demonstrated finely designable $\mathrm{CuO}$ nanomaterials for high-performance visible light photodetectors.

Here, we developed a high-performance visible light photodetector that utilizes a geometrically structured $\mathrm{CuO}$ nanowire (NW) array. To demonstrate the performance-enhanced $\mathrm{CuO}$ photodetector, we proposed a 3-D nanostructure that consists of a perfectly-aligned, dense $\mathrm{CuO} \mathrm{NW}$ array on a silicon dioxide $\left(\mathrm{SiO}_{2}\right)$ nanograting substrate. The proposed nanostructure can be ideal for maximizing and minimizing photocurrent $\left(I_{p h}\right)$ and $I_{d a r k}$, respectively, because a perfectly-aligned NW array not only causes a dramatic reduction in electrical resistivity, but also enhances light absorption based on constructive interference by scattered light. We optimized the geometry of the proposed photodetector using finite-difference time-domain (FDTD) method. Then, to experimentally confirm the performance enhancements, we evaluated various photodetector devices with diverse shapes of $\mathrm{CuO}$ prepared using the developed nanofabrication methods. A parametric analysis of the fabricated device verified the dramatic enhancement in optoelectronic performance of the perfectly-aligned $\mathrm{CuO} \mathrm{NW}$ component. The fabricated devices showed high values of $S, R$, and $D^{*}$, and fast response time $(\tau)$; to the best of our knowledge, these values are at state-of-the-art level among $\mathrm{CuO}$-based photodetectors. Finally, by using the formulated fabrication method, we successfully demonstrated tens of devices in an array on a cm-scale substrate, all of which showed high uniformity and stable optoelectronic characteristics.

\section{Results and discussion}

Figure 1a shows a schematic of the proposed photodetector. The proposed sensor is composed of a perfectlyaligned $\mathrm{CuO} \mathrm{NW}$ array on an $\mathrm{SiO}_{2}$ nanograting substrate. There are two gold (Au) electrodes at both ends of the NWs where the optoelectronic characteristics are measured. Based on these geometrical structures, the proposed photodetector can exhibit high-optoelectronic characteristics because of the size-effect of the confined 
nanoscale and the enhanced light scattering in geometrically designed shape. High optoelectrical characteristics include (1) high sensitivity, (2) reduced response time, and (3) high responsivity, as follows. (1) Higher sensitivity $\left.\left(S=\left(I_{\text {light }}-I_{\text {dark }}\right) / I_{\text {dark }}\right)\right)$ by suppressed $I_{\text {dark }}$ : since the $\mathrm{CuO}$ NW has a nanometer scale cross-sectional dimension, electron (or hole) scattering is frequently generated, resulting in dramatically increased electrical resistivity and reduced $I_{\text {dark }}$. Note that we defined the $\mathrm{CuO} N W$ width as a critical dimension $(C D)$. (2) Reduced $\tau$ by $\mathrm{CuO}$ $\mathrm{NW}$-structure: because the $\mathrm{CD}$ and thickness of $\mathrm{CuO}$ are at nanometer scale, the hole-electron recombination energy barrier $(\Phi)$ can be small. Small energy barrier results in active recombination of photo-generated carriers. Because longer response time is caused by subsequent slow diffusion of free carriers to the $\mathrm{CuO}$ surface, rapid recombination prevents current change by generated free carriers. (3) Higher responsivity $\left(R=I_{p h} /\left(P_{\text {in }} \cdot A\right) ; P_{\text {in }}\right.$ and $A$ are power of incident light and light receiving area, respectively) and higher detectivity with higher $I_{p h}$ : because the $\mathrm{CuO}$ NWs are perfectly aligned with a certain pitch, the NWs do not form unnecessary networks with each other, resulting in an ideal light receiving field without any shaded areas. In particular, the periodic NW array can improve absorption based on the light scattering effect. As light enters the perfectly aligned and periodic $\mathrm{CuO}$ NW array, it is scattered at the surface of the NWs. At this moment, constructive or destructive interference by scattered light can form between the NWs depending on the geometry of the 3-D nanostructure; thus, optimized constructive interference can be induced by designing the shape and pitch of the $\mathrm{CuO} \mathrm{NW}$ array, resulting in an increase of light absorption and higher $I_{p h}$.

To optimize the geometry of the nanostructure to maximally enhance the absorption, we utilized an FDTD simulation to design the geometrical arrangement of the NW array. In the simulation, we first established the $\mathrm{CuO}$ NW array on the $\mathrm{SiO}_{2}$ nanograting structure; the thickness $(t)$ of $\mathrm{CuO}$ NW was $114 \mathrm{~nm}$, width $(w)$, height $(h)$, and pitch $(p)$ of $\mathrm{SiO}_{2}$ nanograting are 200,300 , and $400 \mathrm{~nm}$, respectively. It is worthwhile to note that we also performed FDTD simulation of a CuO thin film of $t=122 \mathrm{~nm}$ with the same unit volume as the NWs to fairly compare the nanostructure effect of the proposed device. Details about the FDTD simulation are included in Supplementary Fig. S1. The calculated E-field intensity in visible light wavelength range $(\lambda=400-700 \mathrm{~nm})$ is shown in Fig. 1b. Comparing the E-field intensity of the $\mathrm{CuO}$ film (Supplementary Fig. S2), notable E-field concentration is additionally generated in the space between the $\mathrm{CuO}$ nanowires (red in Fig. 1b). We can expect that the E-field concentration between the nanostructure causes more light to be absorbed through the sides of the $\mathrm{CuO} \mathrm{NW}$ in the overall visible light range $(\lambda=400-700 \mathrm{~nm})$. Indeed, we confirmed from the simulation results that the light absorption of a nanowire is significantly higher than that of a thin film in the overall visible light range (Fig. 1c), implying the better optoelectronic characteristics of the CuO NW device. With the theoretical confirmation of the proposed concept, it is then essential to optimize the structure of the CuO NW array for maximized performance.

In a periodic structure of $\mathrm{CuO} N W s$, the pitch $(p)$ value is important to optimize the optical performance. This affects not only the light interference, but also the fill factor of the $\mathrm{CuO} \mathrm{NWs,} \mathrm{which} \mathrm{is} \mathrm{important} \mathrm{in} \mathrm{determining}$ the effective light receiving area of $\mathrm{CuO}$ in the entire exposed area. This effective area ultimately determines the amount of absorption of the proposed 3-D nanostructure. The simulation was performed with various values of $p$ of the $\mathrm{CuO} \mathrm{NW}$ array on $\mathrm{SiO}_{2}$ nanograting, from 400 to $1200 \mathrm{~nm}$, having the same geometry of width and thickness $(w=314 \mathrm{~nm}$ and $t=114 \mathrm{~nm})$ of $\mathrm{CuO} \mathrm{NW}$ and height $(h=300 \mathrm{~nm})$ of $\mathrm{SiO}_{2}$ nanograting structure (Fig. 1d). In the calculated visible light range $(\lambda=400-700 \mathrm{~nm})$, the amount of absorption from the $\mathrm{CuO}$ nanowire array on the $\mathrm{SiO}_{2}$ nanograting substrate increases as $p$ decreases. The absorption of light at $550 \mathrm{~nm}$ is plotted with respect to $p$ for quantitative comparison (Fig. 1e). The absorption continuously increases as $p$ becomes smaller from $1200 \mathrm{~nm}$; then, a dramatic increase of absorption is generated as $p$ becomes smaller than $800 \mathrm{~nm}$. Although there is a loss of absorption area due to the gap in which NW is separated, the amount of absorption from the nanowires still exceeds that of a film when $p$ is smaller than $500 \mathrm{~nm}$. This phenomenon is mainly due to constructive interference resulting from the high fill-factor of the $\mathrm{CuO}$ nanowires. The maximum absorption at $p=400 \mathrm{~nm}$ is $\sim 0.8$, which is $115 \%$ of that of the film, implying a significant improvement in optoelectronic performance through higher degree of light absorption due to the smaller dimensions of nanoscale. As shown in Supplementary Fig. S3, the intensity of the E-field can fluctuate with respect to varying $p$ because of constructive and destructive interference between the structures.

Next, we developed a fabrication process that enables us to experimentally confirm the enhanced absorption of the proposed 3-D CuO NW array. The fabrication started with a pre-designed $\mathrm{SiO}_{2}$ nanograting substrate (Fig. 2a,i); the $\mathrm{SiO}_{2}$ nanograting was manufactured from $\mathrm{Si}$ nanograting via wet-chemical size reduction process ${ }^{39}$ and thermal oxidation. The process of preparing the substrate and a scanning electron microscope image of the substrate are shown in Supplementary Fig. S4. The perfectly-aligned NWs were then easily fabricated on the $\mathrm{SiO}_{2}$ nanograting substrate by glanced angled deposition (GLAD) method $\left(\theta=75^{\circ}\right)$ (Fig. 2a,ii). Since the $\mathrm{Cu}$ was deposited on the 3-D nanograting substrate at a specific angle, the 1-D NW of Cu can be formed on the top of the nanograting by shadowing effect. After deposition, the $\mathrm{Cu} N W$ was oxidized at a high temperature $\left(700^{\circ} \mathrm{C}\right.$ for $3 \mathrm{~h}$ in air ambient) to become CuO NW (Fig. 2a,iii). Finally, Au electrodes (thickness $=150 \mathrm{~nm}$ ) are formed on the $\mathrm{CuO}$ nanowires using a conventional lift-off process (Fig. 2a,iv). The details of device fabrication are included in the Methods section. Because all processes including the fabrication of the Si nanograting substrate are compatible with conventional semiconductor manufacturing processes, the proposed nanowire fabrication method is economically advantageous for reliable device fabrication. Visual inspection on the fabricated device was performed using an optical microscope (Fig. 2b) and SEM (Fig. 2c). The CuO NW array was formed on the entire area of the $\mathrm{SiO}_{2}$ nanograting substrate, and the interdigitated shape of the Au electrodes establishes an electrical current pathway through the nanowires in the length-direction. The uniformly isolated $\mathrm{CuO}$ nanowire array without any interconnection between the NWs can be confirmed in the SEM image, which indicates perfectly-aligned $\mathrm{CuO}$ NWs in the width-direction (Fig. 2c). With the fabricated device, we also confirmed, via visible light spectrometer measurements, an enhanced light absorption characteristic of the fabricated $\mathrm{CuO} N W$ 
(a)

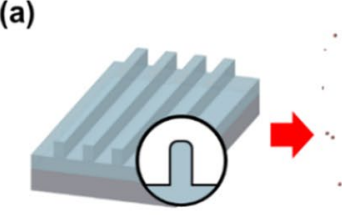

i) $\mathrm{SiO}_{2} / \mathrm{Si}$ nanograting substrate

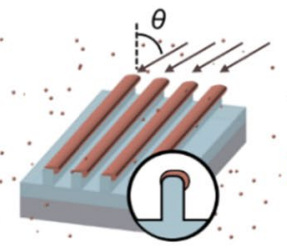

ii) Cu NW deposition (GLAD, $\theta=75^{\circ}$ )

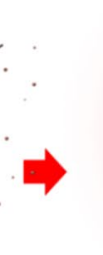

iii)

iii) CuO NWs formation (furnace oxidation)

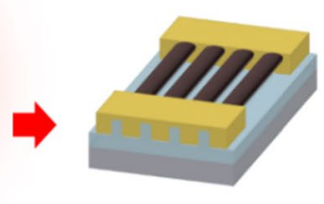

iv) Au electrode lift-off
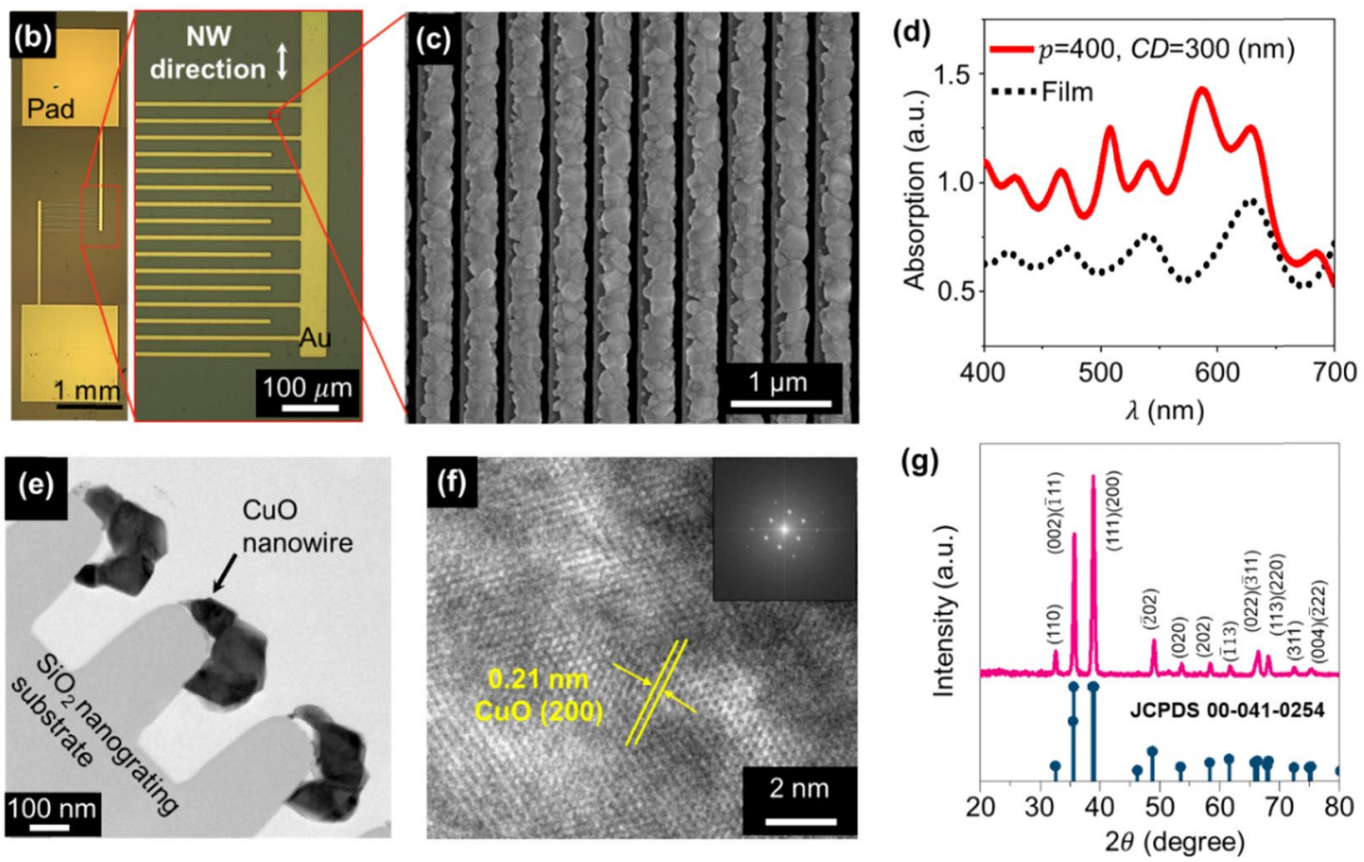

Figure 2. Device demonstration. (a) 3D-schematics of the fabrication process. (b) Optical image of the fabricated device (left panel). The $\mathrm{CuO}$ nanowires are fabricated on the entire area on the substrate. The red dashed box is magnified in the right panel. (c) Top SEM image of the fabricated CuO nanowires. (d) The measured absorption data of the fabricated $\mathrm{CuO}$ nanowires (red solid line) and thin film $\mathrm{CuO}$ (black dashed line). (e) TEM HR mode of fabricated $\mathrm{CuO}$ nanowire (cross-sectional view). (f) Magnified TEM image of CuO NW (inset: Fourier transform pattern of single grain of $\mathrm{CuO}$ ). (g) The measured XRD pattern of the fabricated $\mathrm{CuO}$ nanowire (upper panel) and reference diffraction lines of the monoclinic tenorite phase of $\mathrm{CuO}$ (JCPDS 00-241-0254) (lower panel).

arrays compared to the $\mathrm{CuO}$ film (Fig. 2d). The absorption of the $\mathrm{CuO}$ NW array is higher than that of a CuO film in overall visible-light range; the results are also highly coincident with the simulation results shown in Fig. 1c.

To understand the material quality of the fabricated $\mathrm{CuO}$, material analysis was conducted using TEM, X-ray diffraction (XRD) analysis, energy dispersive X-ray spectroscopy (EDS), and X-ray photoelectron spectroscopy (XPS). The cross-sectional TEM image of the $\mathrm{CuO}$ NWs confirmed that the $\mathrm{CuO}$ nanowires have a granular structure (Fig. 2e). From the TEM image, we also confirmed that the nanowires are formed only on the top of the $\mathrm{SiO}_{2}$ nanograting, as we designed. Using high-resolution (HR) mode and Fourier transform pattern of the TEM, it was confirmed that each grain had a high quality single crystalline structure (Fig. 2f). The crystallinity of the overall $\mathrm{CuO}$ NWs was further evaluated using XRD analysis. The measured XRD data showed that the crystalline $\mathrm{CuO}$ NWs highly matched the diffraction lines of the monoclinic tenorite phase of CuO (JCPDS 00-041-0254) (Fig. 2g). EDS material mapping analysis from the TEM image showed high purity of the CuO nanowires, without any significant material diffusion or degradation (Supplementary Fig. S5). In the XPS measurement results of the chemical-state, $\mathrm{CuO}$ also highly corresponded with the conventional peaks of pure $\mathrm{CuO}$ (Supplementary Fig. S6). By investigating the material properties of $\mathrm{CuO} \mathrm{NW}$, we confirmed that our fabrication method can successfully produce perfectly-aligned $\mathrm{CuO}$ nanowires with high material quality and chemical stability.

Next, we performed optoelectronic characterization of the fabricated device. For the measurement, we established a customized visible light optical set-up using a commercial halogen lamp with parameter analyzer (Fig. 3a). Details of the measurement set-up and information on the light source are included in the Methods section and Supplementary Fig. S7, respectively. First, the current-voltage $(I-V)$ characteristics of the device 
(a)

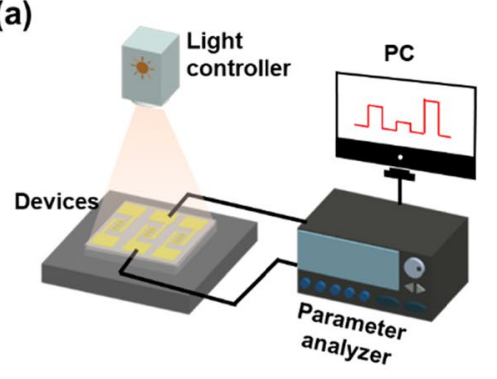

(d)

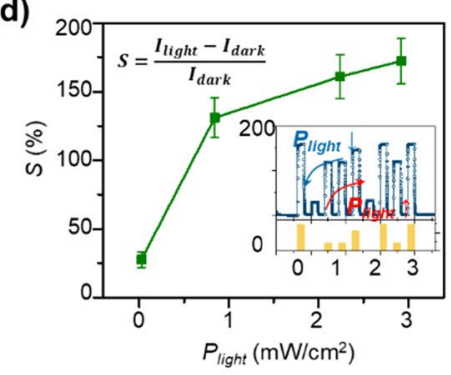

(b)

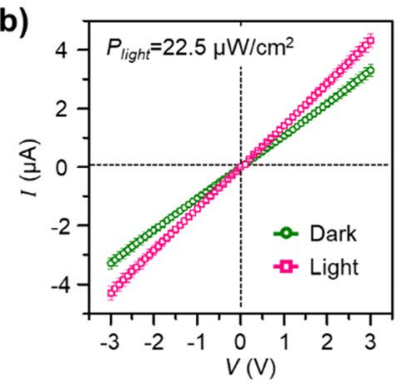

(e)

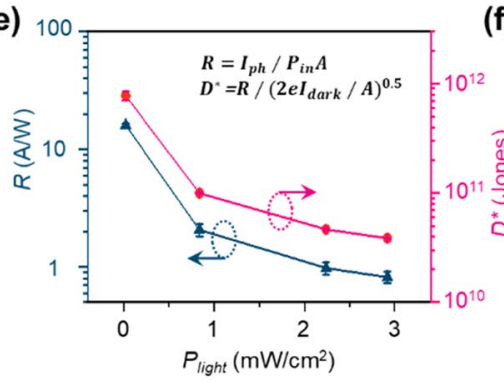

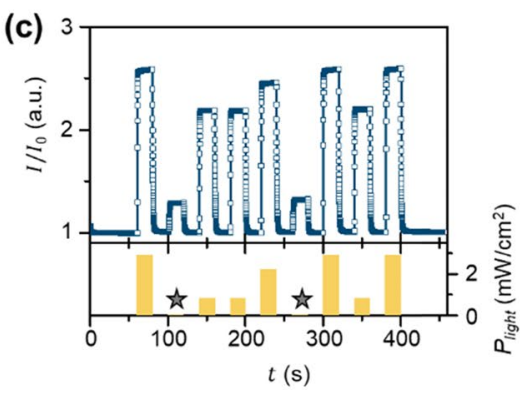

(f)

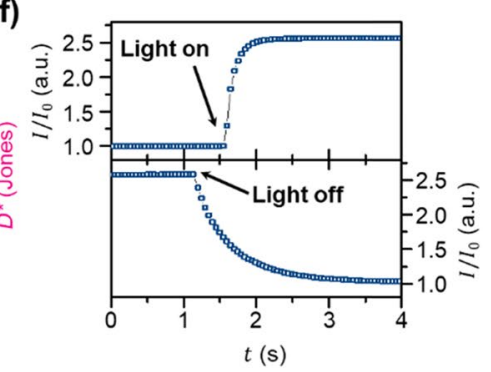

Figure 3. Characterization of the fabricated photodetector. (a) Schematics of the measurement set-up. (b) The measured $I-V$ characteristics of the device (green circle: dark state, pink square: $P_{\text {light }}=22.5 \mu \mathrm{W} / \mathrm{cm}^{2}$ ). (c) The dynamic optoelectronic response of the fabricated photo-detector (upper panel), and the intensity of incident light (gray solid star: $P_{\text {light }}=22.5 \mu \mathrm{W} / \mathrm{cm}^{2}$ ). (d) The calculated sensitivity $(S)$ of the device with respect to various $P_{\text {light }}$ (inset: measured $S$ changes by increasing and decreasing $P_{\text {light }}$ ). e) The calculated photo-responsivity $(R)$ and photo-detectivity $\left(D^{*}\right)$ of the device with respect to various $P_{\text {light }}$. f) The dynamic response of the photodetector for $P_{\text {light }}=22.5 \mu \mathrm{W} / \mathrm{cm}^{2}$; rise time $\left(\tau_{r}\right)$ and decay time $\left(\tau_{d}\right)$ were $0.329 \mathrm{~s}$ and $1.21 \mathrm{~s}$, respectively.

in dark state (the green circle in Fig. 3b) and lighted condition $\left(P_{\text {light }}=22.5 \mu \mathrm{W} / \mathrm{cm}^{2}\right.$, the pink square in Fig. 3b) were measured using three devices with identical dimensions. From the ohmic contact behavior, we performed subsequent optoelectrical measurements at under $3 \mathrm{~V}\left(I_{\text {dark }}=3.29 \mu \mathrm{A}\right)$. To examine the dynamic optoelectronic response of the device at various $P_{\text {light }}$ the normalized $I$ and incident $P_{\text {light }}$ changes with respect to time are plotted in the upper and lower panels of Fig. 3c, respectively. As $P_{\text {light }}$ dynamically changed to $22.5 \mu \mathrm{W} / \mathrm{cm}^{2}, 0.840$ $\mathrm{mW} / \mathrm{cm}^{2}, 2.24 \mathrm{~mW} / \mathrm{cm}^{2}$, and $2.92 \mathrm{~mW} / \mathrm{cm}^{2}$, normalized $I$ changed to $4.24,7.21,8.10$, and $8.52 \mu \mathrm{A}$, respectively. Using an optoelectronic response test and randomly changing $P_{\text {light }}$ (Fig. 3c), we also confirmed that the device showed reproducible and reliable optoelectronic characteristics. To quantitatively understand the optoelectronic characteristics of the proposed device, we evaluated its sensitivity $\left(S=I_{p h} / I_{\text {dark }}\right)$, photo-responsivity $\left(R=I_{p h} /\left(P_{\text {in }}\right.\right.$. $A)$ ), and detectivity $\left(D^{*}=R /\left(2 e I_{\text {dark }} / A\right)^{0.5}\right)$, where $I_{p h}$ is photocurrent $\left(I_{p h}=I_{\text {light }}-I_{\text {dark }}\right), A$ is the illuminated area, and $e$ is $1.6 \times 10^{-19} C$. It should be noted that $A$, representing the exposed area, including nanowire array and the substrate, between the interdigitated electrodes, was $0.0024 \mathrm{~cm}^{2}$. Figure $3 \mathrm{~d}$ shows the measured $S$. When the light intensity was $22.5 \mu \mathrm{W} / \mathrm{cm}^{2}$, the measured sensitivity was $27.50 \%$. $S$ increased to $131.08,160.85$, and $172.21 \%$, when $P_{\text {light }}$ increased to $0.840 \mathrm{~mW} / \mathrm{cm}^{2}, 2.24 \mathrm{~mW} / \mathrm{cm}^{2}$, and $2.92 \mathrm{~mW} / \mathrm{cm}^{2}$, respectively. In the calculation, $P_{\text {light }}$ is measured around the $535 \mathrm{~nm}$ wavelength spectrum. The increase in $S$ with higher intensity can be explained as the result of more free carriers being induced by the higher $P_{\text {light }}$. Notably, the generated photocurrent was not linear. As the light intensity increases, photo-generated electron-hole pairs are saturated; as a result, excess photons cannot be absorbed. More importantly, the proposed device showed negligible hysteresis during increasing and decreasing of the light intensity (inset in Fig. 3d). We believe that this result originates from the suppressed slow oxygen desorption reaction. In bulk $\mathrm{CuO}$, oxygen can diffuse into the bulk and then generate an additional desorption reaction with the electrons induced by the light. However, the nanowire intrinsically has a small volume and most of the $\mathrm{CuO}$ parts initially fully react with oxygen because of the large surface-to-volume ratio. Thus, little additional oxygen desorption is generated in the nanowire. Next, we calculated values of $R$ and $D^{*}$ of the device (Fig. 3e). The calculated $R$ and $D^{*}$ were $16.03 \mathrm{~A} / \mathrm{W}$ and $7.78 \times 10^{11}$ Jones, respectively, at $P_{\text {light }}$ of $22.5 \mu \mathrm{W} / \mathrm{cm}^{2}$. The $R$ and $D^{*}$ decreased as $P_{\text {light }}$ increased; at $P_{\text {light }}=0.840 \mathrm{~mW} / \mathrm{cm}^{2}, 2.24 \mathrm{~mW} / \mathrm{cm}^{2}$, and $2.92 \mathrm{~mW} /$ $\mathrm{cm}^{2}, R=2.07,0.98$, and $0.82 \mathrm{~A} / \mathrm{W}$ and $D^{*}=9.98 \times 10^{10}, 4.66 \times 10^{10}$, and $3.86 \times 10^{10}$, respectively. The decreases in $R$ and $D^{*}$ can also be explained by the saturated depletion of the photo-generated electron-hole pairs under high $P_{\text {light }}$. To evaluate the response time, we quantitatively measured $\tau$, which was defined as the time consumed to generate $90 \%$ change in $I$ by applied $P_{\text {light }}$. $I$ changes induced by $P_{\text {light }}=2.92 \mathrm{~mW} / \mathrm{cm}^{2}$ were measured and plotted with an extended time axis (Fig. 3f). When the light was turned on and off, the photodetector showed an immediate $I$ change, and the measured rise time $\left(\tau_{r}\right)$ and decay time $\left(\tau_{d}\right)$ were $0.329 \mathrm{~s}$ and $1.21 \mathrm{~s}$, respectively.

To clarify the high optoelectronic performance of the proposed photodetector, we further investigated the optoelectronic performances of various photodetectors with perfectly-aligned $\mathrm{CuO}$ NWs on $\mathrm{SiO}_{2}$ nanograting with different shapes. Specifically, the $C D$ of the $\mathrm{CuO}$ NWs are varied: (1) film $(C D=\infty)$, (2) $C D=700 \mathrm{~nm}$, (3) $C D=500 \mathrm{~nm}$, and (4) $C D=300 \mathrm{~nm}$ (Fig. 4a). It is noteworthy that $C D$ is an appropriate design parameter to optimize the higher optoelectronic performances. Not only $C D$ is critically associated with $I_{d a r k}$, but it 
(a)

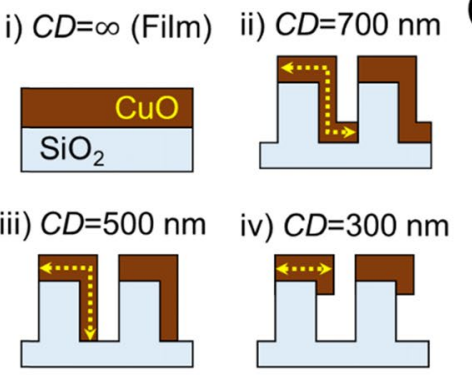

(b)

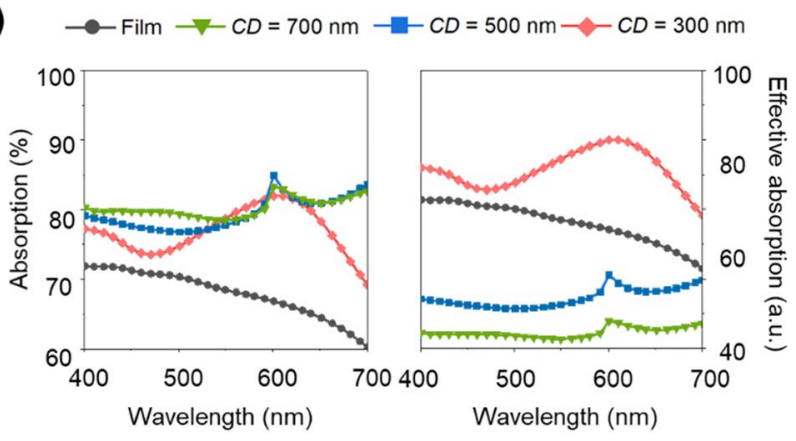

(c)
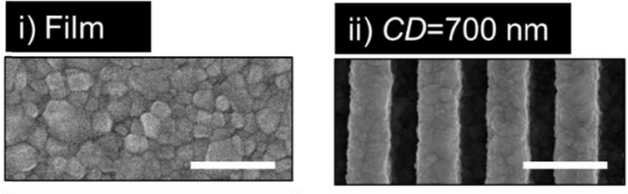

iii) $C D=500 \mathrm{~nm}$

iv) $C D=300 \mathrm{~nm}$
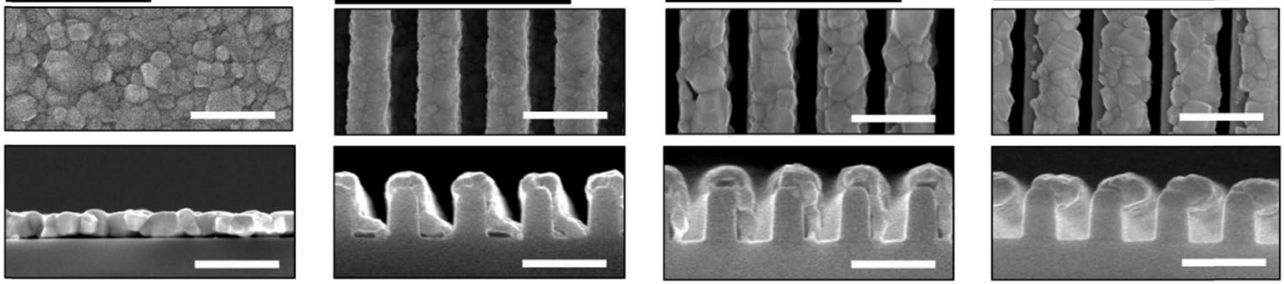

(d)

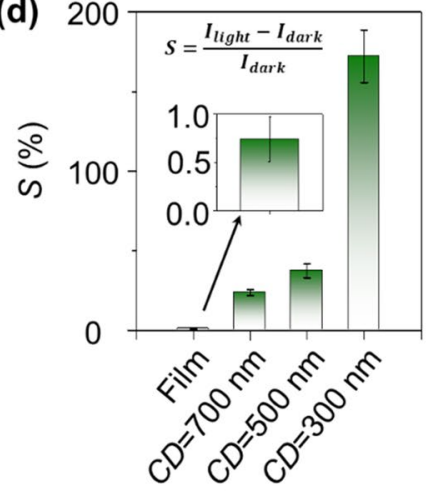

(e)

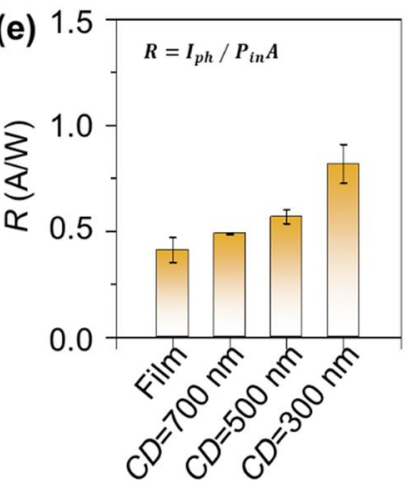

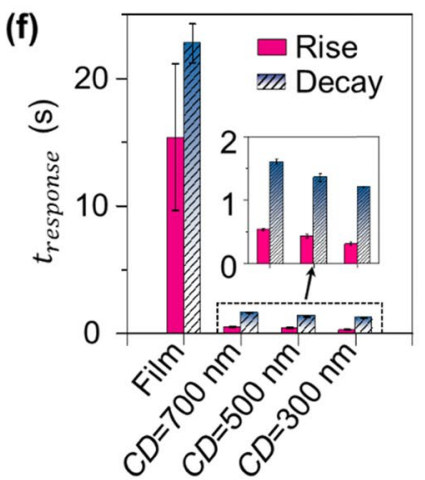

Figure 4. Performance comparison of various device shapes with different critical dimensions (CD). (a) Top (upper panel) and cross-sectional (lower panel) SEM image of various fabricated $\mathrm{CuO}$ shapes. (b) Calculated absorption of NW array with different CDs. (left panel: calculated value, right panel: normalized value using unit volume of $\mathrm{CuO}$ ). (c) Fabricated $\mathrm{CuO}$ film and $\mathrm{CuO}$ NWs with different $\mathrm{CDs}$ (upper panel: top view, lower panel: cross-sectional view/scale bar $500 \mathrm{~nm}$ ). Calculated optoelectrical results in comparison to different $\mathrm{CuO}$ nanostructures having different $C D,(\mathbf{d})$ sensitivity $(S)$, e) photo-responsivity $(R)$, and $(\mathbf{f})$ response time of the fabricated samples. All data are calculated from the optoelectronic response for $P_{\text {light }}=22.5 \mu \mathrm{W} / \mathrm{cm}^{2}$.

can also determine the light-incident area and scattering effect, resulting in different light absorption. Before the experimental study, we calculated the absorption of each case using FDTD. In the visible light spectrum $(\lambda=400-700 \mathrm{~nm}$ ), each case shows different absorption (Fig. 4b). While the film type CuO shows noticeably lower absorption, the $\mathrm{CuO}$ nanostructures present higher absorption. This result can be explained as the result of the enhanced light absorption by scattering at the surface of the $\mathrm{CuO}$ nanostructures, as shown in Fig. $1 \mathrm{~b}$. To evaluate the effective absorption of the various $\mathrm{CuO}$ nanostructures, we further performed normalization of light absorption of each case using unit volume of $\mathrm{CuO}$. Since the optoelectronic performance of the device is determined by the variation of the optoelectronic response of the entire $\mathrm{CuO}$ volume, it is reasonable to consider only the amount of light absorbed at unit $\mathrm{CuO}$ nanostructures. Thus, we calculated the effective absorption of each $\mathrm{CuO}$ nanostructure by dividing the absorption with the volume of $\mathrm{CuO}$. From the calculated results, we can confirm that the highest effective absorption can be achieved for the $C D=300 \mathrm{~nm} \mathrm{CuO}$ structure, and we can explain this phenomenon by referring to the maximized E-field concentration induced by the structure (Supplementary Fig. S8).

To experimentally confirm the design study, we further fabricated photodetector devices having different $C D$ of $\mathrm{CuO}$ (Fig. 4c). The various $\mathrm{CDs}$ of the NW are fabricated by controlling the deposition angle. The 700, 500, and $300 \mathrm{~nm} \mathrm{CuO} \mathrm{NW} \mathrm{CDs} \mathrm{are} \mathrm{fabricated} \mathrm{by} \mathrm{depositing} \mathrm{identical} \mathrm{thicknesses} \mathrm{of} 40 \mathrm{~nm}$ of Cu by GLAD method with $75^{\circ}, 45^{\circ}$, and $23^{\circ}$ angles, respectively, and then performing oxidation $\left(700{ }^{\circ} \mathrm{C}\right.$ in air). First, we measured the $I-V$ characteristics of the devices in a dark state. From the measured $I-V$ curves of the devices, a noticeable variation in electrical resistance was observed with respect to the $C D$ values of the NWs. To clearly compare the 
electrical resistances of the different nanowires, we extracted the sheet resistance of each device in a dark state (Supplementary Fig. S9). At 3 V, the sheet resistance of the film sample was 3.9 Mohms/sq. However, the sheet resistances of other photodetector samples significantly increased as the $C D$ of $\mathrm{CuO}$ decreased; the measured resistances were $120.4,135.0$, and $211.8 \mathrm{Mohms} / \mathrm{sq}$ when the $C D$ values were 700,500 , and $300 \mathrm{~nm}$, respectively. The increase in resistance can be explained by the decrease of $C D$ by the enhanced electron scattering in the nanowire structure. As many studies have previously reported, electron scattering significantly increases as the size of a conductive material decreases, resulting in increased resistance $e^{1,21,22,32,40}$. We further tested the dynamic optoelectronic characteristics of all samples. All devices were exposed to randomly different light, and the optoelectronic responses were measured (Supplementary Fig. S10). For the quantitative comparison, we first extracted $S$ from the optoelectronic response of the samples to $P_{\text {light }}=2.92 \mathrm{~mW} / \mathrm{cm}^{2}$. As the CuO NWs became smaller and $C D$ decreased, an exceptionally higher $S$ was achieved (Fig. 4d). Specifically, $S$ was enhanced by more than 230 times with the $C D=300 \mathrm{~nm}$ nanowire compared to that of the film sample. With the CuO film sample $(C D=\infty)$, the $S$ was $0.74 \%$, and $S$ of the CuO NW samples increased to $23.69,37.23$, and $172.21 \%$, as the $C D$ decreased to 700,500 , and $300 \mathrm{~nm}$. We attribute this dramatic enhancement in $S$ with the $C D=300 \mathrm{~nm}$ device to the successful reduction in $I_{\text {dark }}$ due to electron scattering, which occurred without degrading $I_{p h}$. Next, we extracted the $R$ of the samples (Fig. $4 \mathrm{e}$ ). The $R$ of the nanowire devices was also remarkably higher than that of the film device. The $R$ of the film and of devices with $C D=700,500$, and $300 \mathrm{~nm}$ were $0.41,0.49,0.57$, and 0.82 $\mathrm{A} / \mathrm{W}$, respectively. This represents a 2.0 -times increase in the $C D=300 \mathrm{~nm}$ device compared to the film device. We believe this dramatic enhancement in nanostructure was obtained by scattering effect in the periodic nanostructure, as we have discussed in Fig. 1. Lastly, we compared the $\tau$ of the samples (Fig. $4 \mathrm{f}$ ). $\tau$ was also obtained with $P_{\text {light }}=2.92 \mathrm{~mW} / \mathrm{cm}^{2}$. For the $\mathrm{CuO}$ film sample, $\tau_{r}$ and $\tau_{d}$ were 15.40 and $22.76 \mathrm{~s}$, respectively. In contrast, the nanowire samples achieved greatly reduced values of $\tau_{r}$ and $\tau_{d}$. Specifically, $\tau_{r}$ and $\tau_{d}$ were 0.54 and 1.61 , 0.43 and 1.36 , and 0.31 and $1.21 \mathrm{~s}$ for values of $C D=700,500$, and $300 \mathrm{~nm}$, respectively. These improvements in $\tau$ according to the reduction in $C D$ can be explained by the reduced conductive channel effect ${ }^{41}$. In the smaller $C D$ nanowires, free carriers travel through a smaller area of effective conductive channel; the reduced scale of the effective conductive channel shortens the carrier transit time, which leads to faster $\tau$.

So far, we have verified that the proposed perfectly-aligned $\mathrm{CuO}$ nanowire, based on its unique structural form-factor, enables a high-performance photodetector. To clearly understand the superior optoelectronic performances of the proposed device, we compared the performance of the device $(C D=300 \mathrm{~nm})$ with those of other photodetectors. To the best of our knowledge, compared to recently developed CuO-based photodetectors (Table 1) ${ }^{17-28,30,42}$, the proposed device exhibited state-of-the-art levels of photo-responsivity, photo-detectivity, sensitivity, and response time. One further advantage of the proposed device is its compatibility with conventional semiconductor fabrication. All of the fabrication processes used for the device are conventional semiconductor processes, which helps to ensure device uniformity, reproducibility, and high-throughput. To highlight the advantages in fabrication, we fabricated a 24-device array and evaluated its performance uniformity (Fig. 5a). An optical image of the fabricated device array is shown in Fig. 5a. There was no significant device failure, and all devices showed relatively uniform optoelectronic characteristics (Fig. 5b). The measured $R, D^{*}, \tau_{r}$, and $\tau_{d}$ values at light intensity of $2.92 \mathrm{~mW} / \mathrm{cm}^{2}$ are shown in Fig. $5 \mathrm{~b}$; the average $R, D^{*}, \tau_{r}$, and $\tau_{r}$ of all devices were $0.93 \pm 0.6$ $\mathrm{A} / \mathrm{W}, 2.73 \pm 0.45 \times 10^{10}$ Jones, $0.35 \pm 0.04 \mathrm{~s}$, and $1.39 \pm 0.08 \mathrm{~s}$, respectively. In addition, we tested the operation stability of the fabricated device in repetitive illumination and various environmental conditions. The repetitive operation test was performed more than 100 times with an interval of $30 \mathrm{~s}$ at a light intensity of $2.92 \mathrm{~mW} / \mathrm{cm}^{2}$. The result shows that $I_{\text {light }}$ and $I_{\text {dark }}$ are consistent with the initial values even after the 100th operation (Fig. $5 \mathrm{c}$ ). Next, the relative humidity $(\mathrm{RH})$ was changed from 30 to $60 \%$; however, there was no significant change in optoelectronic performance (Fig. 5d). The device also showed almost identical optoelectronic responses with various incident lights (circle: $22.5 \mu \mathrm{W} / \mathrm{cm}^{2}$, square: $0.840 \mathrm{~mW} / \mathrm{cm}^{2}$, triangle: $2.24 \mathrm{~mW} / \mathrm{cm}^{2}$, and diamond: $2.92 \mathrm{~mW} /$ $\mathrm{cm}^{2}$ ). We believe this result can be attributed to the regular nano-structuring of the device; the device consists of a perfectly-aligned nanowire array, which prohibits surficial coating and coverage by water droplets. We also tested the effect of temperature on the device. As the external temperature increased, values of $R$ and $D^{*}$ of the device increased at the light intensity $=2.92 \mathrm{~mW} / \mathrm{cm}^{2}$ (Fig. 5e). $R$ and $D^{*}$ of the device at $20,40,60$, and $80^{\circ} \mathrm{C}$ were $0.67 \mathrm{~A} / \mathrm{W}$ and $31.81 \times 10^{9}$ Jones, $0.80 \mathrm{~A} / \mathrm{W}$ and $38.24 \times 10^{9}$ Jones, $1.11 \mathrm{~A} / \mathrm{W}$ and $52.84 \times 10^{9}$ Jones, and $1.55 \mathrm{~A} / \mathrm{W}$ and $73.85 \times 10^{9}$ Jones, respectively. These increases in $R$ and $D^{*}$ can be explained by the enhancement in carrier generation induced by external temperature ${ }^{43,44}$. When thermal energy is applied to a semiconductor, additional free carriers, such as electrons and holes, can be generated, and more $I_{p h}$ is induced. Even though temperature can induce a significant variation in performance, it can be compensated for in the future by incorporating an additional temperature sensor. Finally, we measured the change in device performance over time. The device was stored at room temperature condition for 30 days, but there was no significant change in optoelectronic response with incident light (Fig. 5f, circle: $22.5 \mu \mathrm{W} / \mathrm{cm}^{2}$, square: $0.840 \mathrm{~mW} / \mathrm{cm}^{2}$, triangle: $2.24 \mathrm{~mW} / \mathrm{cm}^{2}$, and diamond: $2.92 \mathrm{~mW} / \mathrm{cm}^{2}$ ).

\section{Conclusions}

In conclusion, we have proposed a visible light photodetector with a perfectly-aligned $\mathrm{CuO}$ nanowire array on a 3-D structure. Electrons guided in the inherently narrow nanowires suppress $I_{d a r k}$ and enhance $I_{p h}$. In particular, the periodic characteristic of the perfectly-aligned $\mathrm{CuO}$ nanowires on nanograting substrate with high fill-factor contribute to absorption enhancement via constructive interference effect. Through the simulation of light absorption, and based on device's geometric structure, we optimized the dimensions of the perfectlyaligned $\mathrm{CuO} N W$ s on a nanograting substrate with values of $p=400 \mathrm{~nm}$ and $C D=300 \mathrm{~nm}$. To demonstrate the proposed device, we developed a nanofabrication method to easily fabricate a perfectly-aligned $\mathrm{CuO}$ nanowire array based on a conventional semiconductor process. The fabricated photodetector exhibited high optoelectronic 


\begin{tabular}{|c|c|c|c|c|c|c|c|}
\hline References & Structure & $\begin{array}{l}\text { Light source/ } \\
\text { applied voltage }\end{array}$ & Responsivity $[\mathrm{A} / \mathrm{W}]$ & Detectivity [Jones] & $\begin{array}{l}\text { Response time } \\
\text { (rise/fall) }\end{array}$ & Sensitivity (\%) & Fabrication process \\
\hline This work & $\begin{array}{l}\text { Perfectly- aligned } \\
\text { nanowire array }\end{array}$ & $\begin{array}{l}\text { Visible light } \\
(400-700 \mathrm{~nm}) / 3 \mathrm{~V}\end{array}$ & $\begin{array}{l}16.0 \mathrm{~A} / \mathrm{W} \\
\left.\mu \mathrm{W} / \mathrm{cm}^{2}\right)\end{array}\left(P_{i n}=22.5\right.$ & $\begin{array}{l}7.78 \times 10^{11} \\
\left(P_{\text {in }}=22.5 \mu \mathrm{W} / \mathrm{cm}^{2}\right)\end{array}$ & $0.31 \mathrm{~s} / 1.21 \mathrm{~s}$ & $\begin{array}{l}172.2\left(P_{i n}=2.92\right. \\
\left.\mathrm{mW} / \mathrm{cm}^{2}\right)\end{array}$ & $\begin{array}{l}\text { Semiconductor } \\
\text { batch-process }\end{array}$ \\
\hline $\begin{array}{l}\text { Appl. Surf. Sci. 2015, } \\
346,18-23\end{array}$ & Film & $\begin{array}{l}\text { Visible light } \\
\left(520 \mathrm{~nm}, P_{i n}=1\right. \\
\left.\mathrm{mW} / \mathrm{cm}^{2}\right) / 2 \mathrm{~V}\end{array}$ & $\sim 11 \times 10^{-3}$ & N/A & $\mathrm{N} / \mathrm{A} /<1 \mu \mathrm{s}$ & $\sim 3$ & $\begin{array}{l}\text { Physical vapor } \\
\text { deposition }\end{array}$ \\
\hline $\begin{array}{l}\text { Superlattice. Micro- } \\
\text { struct. 2018, 113, } \\
754-760\end{array}$ & Film & $\begin{array}{l}\text { Visible light } \\
\left(650 \mathrm{~nm}, P_{\text {in }}=5\right. \\
\left.\mathrm{mW} / \mathrm{cm}^{2}\right) / 5 \mathrm{~V}\end{array}$ & $5.9 \times 10^{-4}$ & $4.60 \times 10^{8}$ & $52.28 \mathrm{~s} / 44.2 \mathrm{~s}$ & 57.5 & $\begin{array}{l}\text { Physical vapor } \\
\text { deposition }\end{array}$ \\
\hline $\begin{array}{l}\text { Sci. Rep. 2019, 9, } \\
7334\end{array}$ & Film & $\begin{array}{l}\text { Visible light } \\
(400-700 \mathrm{~nm}) / 3 \mathrm{~V}\end{array}$ & $\begin{array}{l}15.3 \mathrm{~A} / \mathrm{W}\left(P_{i n}=22.5\right. \\
\left.\mu \mathrm{W} / \mathrm{cm}^{2}\right)\end{array}$ & $\begin{array}{l}1.08 \times 10^{11}\left(P_{\text {in }}=22.5\right. \\
\left.\mu \mathrm{W} / \mathrm{cm}^{2}\right)\end{array}$ & $0.682 \mathrm{~s} / 1.77 \mathrm{~s}$ & $\begin{array}{l}4.06\left(P_{\text {in }}=0.840\right. \\
\left.\mathrm{mW} / \mathrm{cm}^{2}\right)\end{array}$ & $\begin{array}{l}\text { Semiconductor } \\
\text { batch-process }\end{array}$ \\
\hline $\begin{array}{l}\text { IEEE Electron Device } \\
\text { Lett. 2017, 39. 1. } 47\end{array}$ & Film & $\begin{array}{l}\text { Visible light } \\
\left(633 \mathrm{~nm}, P_{\text {in }}=500\right. \\
\left.\mathrm{mW} / \mathrm{cm}^{2}\right) /-20 \mathrm{~V}\end{array}$ & 0.17 & $1.38 \times 10^{11}$ & $0.48 \mathrm{~s} / 0.53 \mathrm{~s}$ & 33.3 & Sol-gel \\
\hline $\begin{array}{l}\text { IEEE Electron Device } \\
\text { Lett. } 2018,40.2 .255\end{array}$ & Film & $\begin{array}{l}\mathrm{UV}(245 \mathrm{~nm}, \\
P_{i n}=2.11 \mathrm{~mW} / \\
\left.\mathrm{cm}^{2}\right) /-20 \mathrm{~V}\end{array}$ & 7.77 & $3.08 \times 10^{11}$ & N/A & 820 & $\begin{array}{l}\text { Solution process and } \\
\text { thermal oxidation }\end{array}$ \\
\hline $\begin{array}{l}\text { Appl. Surf. Sci. 2018, } \\
452,155-164\end{array}$ & $\begin{array}{l}\text { Dispersed nano- } \\
\text { particle }\end{array}$ & $\begin{array}{l}\text { UV-NIR } \\
\left(P_{\text {in }}=A M 1.5 \mathrm{G}\right) / 2 \mathrm{~V}\end{array}$ & 5.4 & $3.28 \times 10^{10}$ & $16 \mathrm{~ns}$ & 45 & Synthesis \\
\hline $\begin{array}{l}\text { J. Phys. Chem. } \\
\text { C 2010, 114, } \\
\text { 2440-2447 }\end{array}$ & Single nanowire & $\begin{array}{l}\text { Visible light } \\
\left(540 \mathrm{~nm}, P_{i n}=1\right. \\
\left.\mathrm{mW} / \mathrm{cm}^{2}\right)\end{array}$ & $\sim 8$ & N/A & $\mathrm{N} / \mathrm{A} / \sim 36 \mathrm{~s}$ & $\begin{array}{l}87\left(P_{\text {in }}=45 \mathrm{~mW} /\right. \\
\left.\mathrm{cm}^{2}\right)\end{array}$ & $\begin{array}{l}\text { Synthesis and } \\
\text { transfer }\end{array}$ \\
\hline $\begin{array}{l}\text { Mater. Lett. 2014, } \\
117,217-220\end{array}$ & Dispersed nanowires & $\begin{array}{l}\text { Visible light } \\
\left(405 \mathrm{~nm}, P_{\text {in }}=11.1\right. \\
\left.\mathrm{mW} / \mathrm{cm}^{2}\right)\end{array}$ & N/A & N/A & N/A/0.45 s & 4 & Thermal oxidation \\
\hline $\begin{array}{l}\text { Nanoscale Res. Lett. } \\
2014,9,637\end{array}$ & Single nanowire & $\begin{array}{l}\text { Visible light } \\
\left(600 \mathrm{~nm}, P_{i n}=2\right. \\
\left.\mathrm{mW} / \mathrm{cm}^{2}\right) / 5 \mathrm{~V}\end{array}$ & 200 & $6.38 \times 10^{11}$ & N/A & 1.35 & Electrochemical \\
\hline $\begin{array}{l}\text { Appl. Phys. Lett. } \\
\text { 2020, 116, } 111102\end{array}$ & $\begin{array}{l}\text { Nano-semiparab- } \\
\text { oloids }\end{array}$ & $\begin{array}{l}\text { UV-NIR }(250- \\
900 \mathrm{~nm}, P_{\text {in }}=5 \mathrm{~mW} / \\
\left.\mathrm{cm}^{2}\right) / 20 \mathrm{~V}\end{array}$ & $2.6 \times 10^{-3}$ & $2 \times 10^{9}$ & N/A & 1.25 & $\begin{array}{l}\text { Hydrothermal } \\
\text { method }\end{array}$ \\
\hline $\begin{array}{l}\text { Small Methods 2021, } \\
2100202\end{array}$ & $\begin{array}{l}\text { Microhemisphere- } \\
\text { Nanowire }\end{array}$ & $\begin{array}{l}\text { NIR }(810 \mathrm{~nm}, \\
P_{\text {in }}=7.4 \mathrm{~mW} / \\
\left.\mathrm{cm}^{2}\right) / 1 \mathrm{~V}\end{array}$ & $2.5 \times 10^{-7}$ & $4.3 \times 10^{8}$ & $18.3 / 144.9$ & 1.3 & $\begin{array}{l}\text { Thermal oxidation } \\
\text { growth }\end{array}$ \\
\hline $\begin{array}{l}\text { ACS applied materi- } \\
\text { als and interfaces } \\
2010,2.5 .1536\end{array}$ & $\begin{array}{l}\text { Mesoporous dan- } \\
\text { delion }\end{array}$ & Visible light & N/A & N/A & $46 \mathrm{~s} / 29.8 \mathrm{~s}$ & N/A & $\begin{array}{l}\text { Synthesis (hydro- } \\
\text { thermal method) }\end{array}$ \\
\hline $\begin{array}{l}\text { Sens. Actuators, } A \\
\text { 2016, 239. } 209\end{array}$ & Nano rod array & $\begin{array}{l}\text { NIR }(760-910 \mathrm{~nm}, \\
P_{i n}=0.1 \mathrm{~mW} / \\
\left.\mathrm{cm}^{2}\right) / 2 \mathrm{~V}\end{array}$ & 1.6 & N/A & $0.41 \mathrm{~s} / 0.25 \mathrm{~s}$ & 700 & $\begin{array}{l}\text { Cu synthesis (aque- } \\
\text { ous solution) and } \\
\text { oxidation }\end{array}$ \\
\hline $\begin{array}{l}\text { IEEE Electron Device } \\
\text { Letters, 2021, 42.6: } \\
875-878\end{array}$ & Nano-composite & $\begin{array}{l}\text { UV-NIR }(600 \mathrm{~nm}, \\
\left.P_{\text {in }}=0.168 \mu \mathrm{W}\right) /- \\
1 \mathrm{~V}\end{array}$ & 8.74 & $2.78 \times 10^{13}$ & $12.16 \mu \mathrm{s} / 26.71 \mu \mathrm{s}$ & $3.75-55.16$ & $\begin{array}{l}\text { Solution process and } \\
\text { spin coating }\end{array}$ \\
\hline
\end{tabular}

Table 1. Comparison of the performance of recently developed $\mathrm{CuO}$ photodetectors.

performance, including values of $S=172.21 \%, R=16.03 \mathrm{~A} / \mathrm{W}, D^{*}=7.78 \times 10^{11}$ Jones, and $\tau_{r} / \tau_{d}=0.31 / 1.21 \mathrm{~s}$. These values are the highest levels reported for $\mathrm{CuO}$ based photodetectors. We also confirmed that the proposed device can be operated with high stability at various levels of humidity $(30-60 \% \mathrm{RH})$ and temperature $\left(20-80{ }^{\circ} \mathrm{C}\right)$. The device exhibited excellent durability over 100 cycles of operation and its performance did not degrade even after 30 days in ambient environment. Finally, we demonstrated a 24-array photodetector with no significant device failure during fabrication; all devices showed great uniformity in values of $R, D^{*}$, and $\tau_{r} / \tau_{d}$. The proposed method offers a guide in that the geometrical arrangement of nanomaterials is a forefront method for designing high-performance photodetector structures that consider light-matter interaction. The proposed concept also provides a valuable example of geometrically structured nanomaterials, which have recently attracted interest in the fields of materials and nanoengineering.

\section{Methods}

Fabrication of $\mathrm{SiO}_{2}$ nanograting substrate. The silicon ( $\mathrm{Si}$ ) nanograting substrate (150 nm-width and $200 \mathrm{~nm}$-space) was first fabricated using $\mathrm{KrF}$ lithography. Then, the $200 \mathrm{~nm}$-width nanograting was reduced to $90 \mathrm{~nm}$-width by repetitive size reduction based on the Si surface oxidation and etching technique. This size reduction was conducted before $\mathrm{Si}$ oxidation, because significant volume expansion is generated by the oxidation process. Then, a wet oxidation process ( $140 \mathrm{~min}, 1100^{\circ} \mathrm{C}$ in $\mathrm{H}_{2}, \mathrm{O}_{2}$ ambient) was conducted on the $70 \mathrm{~nm}$ width $\mathrm{Si}$ nanograting substrate to form silicon dioxide $\left(\mathrm{SiO}_{2}\right)$ on the surface. $\mathrm{SEM}$ images of the $\mathrm{SiO}_{2}$ nanograting substrate fabrication are shown in Supplementary Fig. S4.

Fabrication of photodetector. Perfectly-aligned nanowires were fabricated by oblique PVD at different angles for different $C D$. To produce $C D=300,500$, and $700 \mathrm{~nm}$ devices, $\mathrm{Cu}$ was deposited with identical thicknesses $(40 \mathrm{~nm})$ at angles of $75^{\circ}, 45^{\circ}$, and $23^{\circ}$, respectively. After deposition, $\mathrm{CuO}$ was formed by thermal anneal- 
(a)

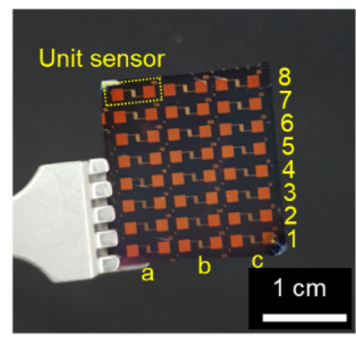

(b)

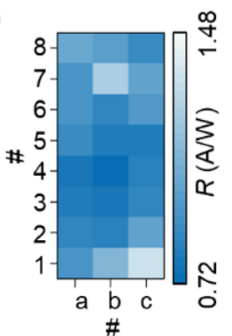

$\frac{1}{2}$
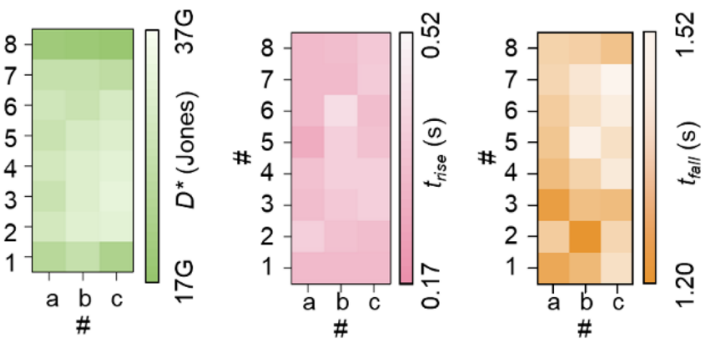

(c)
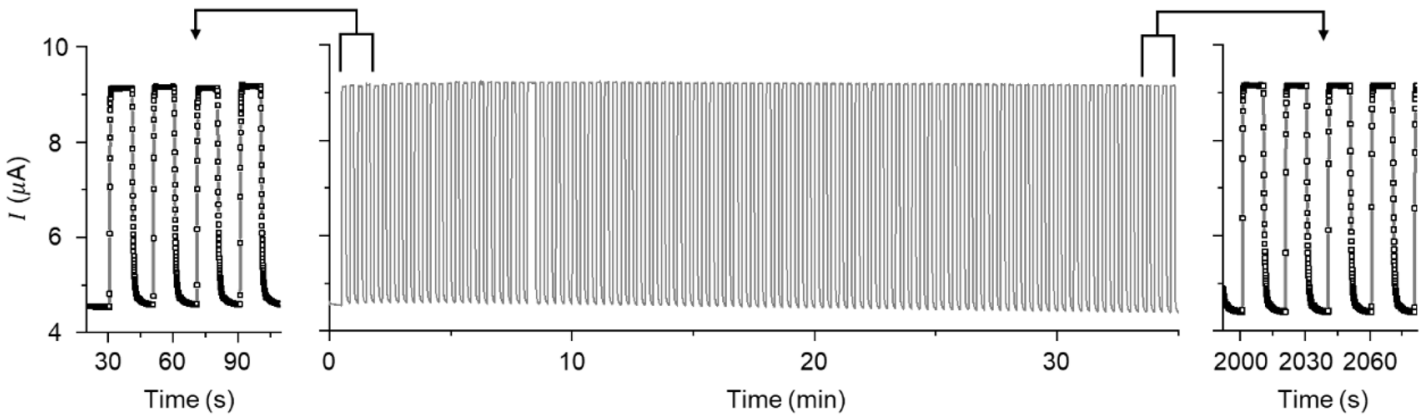

200020302060

Time (s)

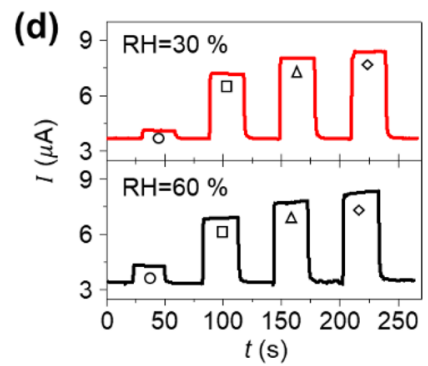

(e)

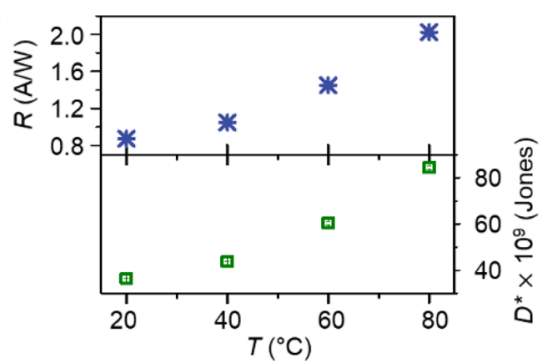

(f)

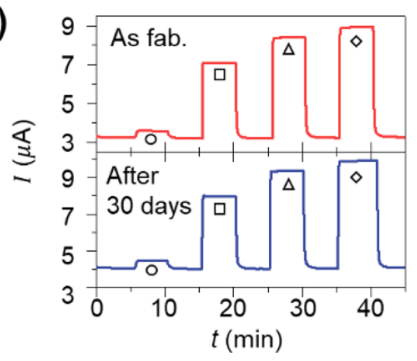

Figure 5. (a) Optical image of the fabricated 24-unit device array. (b) Photo-responsivity $(R)$, photo-detectivity $\left(D^{*}\right)$, and rise $\left(\tau_{r}\right)$ and decay $\left(\tau_{d}\right)$ time of the fabricated device array. (c) 100-times repetitive illumination test with $P_{\text {light }}=2.92 \mathrm{~mW} / \mathrm{cm}^{2}$. Performance stability of the device within various environmental conditions. (d-f) Stability of the fabricated device. Optoelectronic characteristics in different humidity conditions $(\mathbf{d})$, and $R$, $D^{*}$ changes of the device with respect to external temperature (e). Optoelectronic characteristic changes after 30 days (f).

ing process $\left(700{ }^{\circ} \mathrm{C}\right.$ for $1 \mathrm{~h}$ in air atmosphere with heating rate of $10^{\circ} \mathrm{C} / \mathrm{min}$ and natural cooling). Photoresist (NR9-3000PY, Futurrex, Inc.) was applied to the substrate using a spin coating process (thickness $=2.2 \mu \mathrm{m}$, $4000 \mathrm{rpm}, 40 \mathrm{~s}$ ), where the $\mathrm{CuO}$ nanowire formed, to pattern the area of the electrode. A mask aligner (MJB4, SUS MicroTec) was used for the photolithography process. For the interdigitated electrodes with adhesion layer, $10 \mathrm{~nm}$-thickness of chromium (Cr) and $150 \mathrm{~nm}$-thickness of gold ( $\mathrm{Au}$ ) were deposited on the $\mathrm{CuO}$ patterned substrate using PVD. Finally, the photoresist was removed in acetone solution for $1 \mathrm{~min}$. during sonication. Fabrication details are shown in Supplementary Fig. S11.

Characterization of the photodetector. The measurement set-up was established with a probe station chamber, commercial vacuum probe station (MST 5500B, MS tech), parameter analyzer (Keithley 2636B, Tektronix Co.), programmed personal computer, and lamp (halogen-Fok-100 W, Fiber Optic Korea Co., LTD) with intensity controller. For the measurement, the device was held on the probe station by vacuum, and Au electrical probes were gently connected to the Au electrodes of the device. For the dark state, the chamber was closed, and the area around the device was maintained in the dark. The spectrum of the light source is shown in Supplementary Fig. S6.

Received: 30 September 2021; Accepted: 24 January 2022

Published online: 10 February 2022

\section{References}

1. Khan, F., Jan, S. R., Tahir, M. \& Khan, S. in 2015 International Conference on Connected Vehicles and Expo (ICCVE). 259-262 (IEEE).

2. Huo, N. \& Konstantatos, G. Recent progress and future prospects of 2D-based photodetectors. Adv. Mater. 30, 1801164 (2018). 
3. Minotto, A. et al. Visible light communication with efficient far-red/near-infrared polymer light-emitting diodes. Light Sci. Appl. 9, 1-11 (2020).

4. Zhu, Q.-B. et al. A flexible ultrasensitive optoelectronic sensor array for neuromorphic vision systems. Nat. Commun. 12, 1-7 (2021).

5. Li, W. et al. Visible to near-infrared photodetection based on ternary organic heterojunctions. Adv. Funct. Mater. 29, 1808948 (2019).

6. Yang, D. \& Ma, D. Development of organic semiconductor photodetectors: From mechanism to applications. Adv. Opt. Mater. 7, $1800522(2019)$.

7. Kannichankandy, D. et al. Paper based organic-inorganic hybrid photodetector for visible light detection. Appl. Surf. Sci. 524, 146589 (2020).

8. Ren, Z. et al. Bilayer PbS quantum dots for high-performance photodetectors. Adv. Mater. 29, 1702055 (2017).

9. Livache, C. et al. A colloidal quantum dot infrared photodetector and its use for intraband detection. Nat. Commun. 10, 1-10 (2019).

10. Pataniya, P. M. \& Sumesh, C. WS2 nanosheet/graphene heterostructures for paper-based flexible photodetectors. ACS Appl. Nano Mater. 3, 6935-6944 (2020).

11. Kim, K. S. et al. Ultrasensitive MoS 2 photodetector by serial nano-bridge multi-heterojunction. Nat. Commun. 10, 1-10 (2019).

12. Ferhati, H., Djeffal, F. \& Martin, N. Highly improved responsivity of self-powered UV-visible photodetector based on TiO2/Ag/ $\mathrm{TiO} 2$ multilayer deposited by GLAD technique: Effects of oriented columns and nano-sculptured surface. Appl. Surf. Sci. 529, 147069 (2020).

13. Hong, Q. et al. Self-powered ultrafast broadband photodetector based on $\mathrm{p}-\mathrm{n}$ heterojunctions of $\mathrm{CuO} / \mathrm{Si}$ nanowire array. ACS Appl. Mater. Interfaces 6, 20887-20894 (2014).

14. Liu, X., Du, H., Wang, P., Lim, T.-T. \& Sun, X. W. A high-performance UV/visible photodetector of $\mathrm{Cu}_{2} \mathrm{O} / \mathrm{ZnO}$ hybrid nanofilms on SWNT-based flexible conducting substrates. J. Mater. Chem. C 2, 9536-9542 (2014).

15. Zhang, Q. et al. $\mathrm{CuO}$ nanostructures: Synthesis, characterization, growth mechanisms, fundamental properties, and applications. Prog. Mater. Sci. 60, 208-337 (2014).

16. Nomura, K. et al. Room-temperature fabrication of transparent flexible thin-film transistors using amorphous oxide semiconductors. Nature 432, 488-492 (2004).

17. Song, H.-J. et al. High-performance copper oxide visible-light photodetector via grain-structure model. Sci. Rep. 9, 1-10 (2019).

18. Tripathi, A., Dixit, T., Agrawal, J. \& Singh, V. Bandgap engineering in CuO nanostructures: Dual-band, broadband, and UV-C photodetectors. Appl. Phys. Lett. 116, 111102 (2020).

19. Hansen, B. J. et al. Transport, analyte detection, and opto-electronic response of p-type $\mathrm{CuO}$ nanowires. J. Phys. Chem. C 114, 2440-2447 (2010).

20. Manna, S., Das, K. \& De, S. Template-free synthesis of mesoporous $\mathrm{CuO}$ dandelion structures for optoelectronic applications. ACS Appl. Mater. Interfaces 2, 1536-1542 (2010).

21. Ko, Y. H., Nagaraju, G., Lee, S. H. \& Yu, J. S. Facile preparation and optoelectronic properties of $\mathrm{CuO}$ nanowires for violet light sensing. Mater. Lett. 117, 217-220 (2014).

22. Luo, L.-B. et al. One-dimensional CuO nanowire: Synthesis, electrical, and optoelectronic devices application. Nanoscale Res. Lett. 9, 1-8 (2014).

23. Hong, M.-J., Lin, Y.-C., Chao, L.-C., Lin, P.-H. \& Huang, B.-R. Cupric and cuprous oxide by reactive ion beam sputter deposition and the photosensing properties of cupric oxide metal-semiconductor-metal Schottky photodiodes. Appl. Surf. Sci. 346, 18-23 (2015).

24. Chahrour, K. M., Ahmed, N. M., Hashim, M., Elfadill, N. G. \& Bououdina, M. Self-assembly of aligned CuO nanorod arrays using nanoporous anodic alumina template by electrodeposition on Si substrate for IR photodetectors. Sens. Actuators A 239, 209-219 (2016).

25. Lee, S. et al. Sol-gel processed p-type CuO phototransistor for a near-infrared sensor. IEEE Electron. Device Lett. 39, 47-50 (2017).

26. Dixit, T. et al. Solution-processed transparent $\mathrm{CuO}$ thin films for solar-blind photodetection. IEEE Electron. Device Lett. 40, 255-258 (2018).

27. Jana, R. et al. Improving performance of device made up of $\mathrm{CuO}$ nanoparticles synthesized by hydrothermal over the reflux method. Appl. Surf. Sci. 452, 155-164 (2018).

28. Raghavendra, P., Bhat, J. \& Deshpande, N. Visible light sensitive cupric oxide metal-semiconductor-metal photodetectors. Superlatt. Microstruct. 113, 754-760 (2018).

29. Tawfik, W. Z., Khalifa, Z. S., Abdel-wahab, M. S. \& Hammad, A. H. Sputtered cobalt doped CuO nano-structured thin films for photoconductive sensors. J. Mater. Sci. Mater. Electron. 30, 1275-1281 (2019).

30. Dai, T. et al. In situ assembly of ordered hierarchical $\mathrm{CuO}$ microhemisphere nanowire arrays for high-performance bifunctional sensing applications. Small Methods https://doi.org/10.1002/smtd.202100202 (2021).

31. Singh, S. J. \& Chinnamuthu, P. Highly efficient natural-sunlight-driven photodegradation of organic dyes with combustion derived Ce-doped $\mathrm{CuO}$ nanoparticles. Colloids Surf. A Physicochem. Eng. Aspects 625, 126864 (2021).

32. Clifford, J. P. et al. Fast, sensitive and spectrally tuneable colloidal-quantum-dot photodetectors. Nat. Nanotechnol. 4, 40 (2009).

33. Lin, Q. et al. Inverted nanocone-based thin film photovoltaics with omnidirectionally enhanced performance. ACS Nano 8, 6484-6490 (2014).

34. Li, M. et al. Plasmonic biomimetic nanocomposite with spontaneous subwavelength structuring as broadband absorbers. ACS Energy Lett. 3, 1578-1583 (2018).

35. Wang, W. \& Qi, L. Light management with patterned micro-and nanostructure arrays for photocatalysis, photovoltaics, and optoelectronic and optical devices. Adv. Funct. Mater. 29, 1807275 (2019).

36. Zhan, Y. et al. A butterfly-inspired hierarchical light-trapping structure towards a high-performance polarization-sensitive perovskite photodetector. Angew. Chem. 131, 16608-16614 (2019).

37. Narasimhan, V. et al. Multifunctional biophotonic nanostructures inspired by the longtail glasswing butterfly for medical devices. Nat. Nanotechnol. 13, 512-519 (2018).

38. Seo, M. H., Yoo, J. Y., Jo, M. S. \& Yoon, J. B. Geometrically structured nanomaterials for nanosensors, NEMS, and nanosieves. $A d v$. Mater. 32, 1907082 (2020).

39. Jo, M.-S., Choi, K.-W., Seo, M.-H. \& Yoon, J.-B. Realization of large-scale sub-10 nm nanogratings using a repetitive wet-chemical oxidation and etching technique. Micro Nano Syst. Lett. 5, 1-7 (2017).

40. Miao, J. et al. Single InAs nanowire room-temperature near-infrared photodetectors. ACS Nano 8, 3628-3635 (2014).

41. Wu, P., Dai, Y., Ye, Y., Yin, Y. \& Dai, L. Fast-speed and high-gain photodetectors of individual single crystalline Zn 3 P 2 nanowires. J. Mater. Chem. 21, 2563-2567 (2011).

42. Srivastava, A., Singh, R., Jit, S. \& Tripathi, S. Pentacene and $\mathrm{CuO}$ nanocomposite based self-powered broadband photodetector. IEEE Electron. Device Lett. 42, 875-878 (2021).

43. Qi, J., Ma, N., Ma, X., Adelung, R. \& Yang, Y. Enhanced photocurrent in $\mathrm{BiFeO}_{3}$ materials by coupling temperature and thermophototronic effects for self-powered ultraviolet photodetector system. ACS Appl. Mater. Interfaces 10, 13712-13719 (2018).

44. Yang, Y. et al. The enhanced photocurrent of epitaxial BiFeO3 film at 130 C. J. Appl. Phys. 119, 044102 (2016). 


\section{Acknowledgements}

This work was supported by the National Research Foundation of Korea(NRF) Grant funded by the Korea government(MSIT) (No. NRF-2021R1A5A1032937, NRF-2021R1F1A105775411). This work was supported by the National Research Foundation of Korea(NRF) Grant funded by the Korea Government(MSIT) (No. NRF-2021R1A2C201071411).

\section{Author contributions}

H.-J.S. and M.-H.S. conceived the idea. M.-S.J., Y.-K.S. and S.-M.K. contributed to the experiments and analyzed data. B.-J.K. and X.T. contributed to the FDTD simulation. J.-B.Y. inspired the research, with guidance, and participated in data analysis. The manuscript and all figures were written and drawn, respectively, by M.-H.S., M.-S.J., B.-J.K., S.-H.K. and J.-B.Y. All authors discussed the results and commented on the manuscript.

\section{Competing interests}

The authors declare no competing interests.

\section{Additional information}

Supplementary Information The online version contains supplementary material available at https://doi.org/ 10.1038/s41598-022-06031-y.

Correspondence and requests for materials should be addressed to M.-H.S. or J.-B.Y.

Reprints and permissions information is available at www.nature.com/reprints.

Publisher's note Springer Nature remains neutral with regard to jurisdictional claims in published maps and institutional affiliations.

(c) (i) Open Access This article is licensed under a Creative Commons Attribution 4.0 International License, which permits use, sharing, adaptation, distribution and reproduction in any medium or format, as long as you give appropriate credit to the original author(s) and the source, provide a link to the Creative Commons licence, and indicate if changes were made. The images or other third party material in this article are included in the article's Creative Commons licence, unless indicated otherwise in a credit line to the material. If material is not included in the article's Creative Commons licence and your intended use is not permitted by statutory regulation or exceeds the permitted use, you will need to obtain permission directly from the copyright holder. To view a copy of this licence, visit http://creativecommons.org/licenses/by/4.0/.

(C) The Author(s) 2022 